Relations industrielles

Industrial Relations

\title{
La participation ouvrière
}

\section{Jean-Pierre Després}

Volume 2, numéro 5, janvier 1947

URI : https://id.erudit.org/iderudit/1023833ar

DOI : https://doi.org/10.7202/1023833ar

Aller au sommaire du numéro

Éditeur(s)

Département des relations industrielles de l’Université Laval

ISSN

0034-379X (imprimé)

1703-8138 (numérique)

Découvrir la revue

Citer cet article

Després, J.-P. (1947). La participation ouvrière. Relations industrielles /

Industrial Relations, 2(5), 5-5. https://doi.org/10.7202/1023833ar

Tous droits réservés (C Département des relations industrielles de l’Université Laval, 1947
Ce document est protégé par la loi sur le droit d'auteur. L'utilisation des services d'Érudit (y compris la reproduction) est assujettie à sa politique d'utilisation que vous pouvez consulter en ligne.

https://apropos.erudit.org/fr/usagers/politique-dutilisation/ 


\section{Face à l'avenir}

\section{LA PARTIICIPATION OUVRIÈRE}

Les deux revendications essentielles de la classe ouvrière après la première Grande Guerre ont été la journée de huit heures et le respect de la liberté syndicale. De nos jours ces revendications semblent avoir été satisfaites dans la plupart des pays, grâce à l'action persévérante des syndicats ouvriers et à l'intervention gouvernementale, bien que certains secteurs de la classe patronale aient mis quinze années à se convaincre qué la liberté syndicale découle de la démocratie politique et de l'économie capitaliste.

Depuis six ou sept ans des progrès considérables ont été accomplis dans le domaine des relations industrielles. Le syndicalisme s'est discipliné et, d'autre part, la classe patronale a accepté le syndicalisme comme un fait social permanent. L'Etat cherche constamment à rapprocher le Capital et le Travail en les associant étroitement à sa législation, soit sur le plan de la consuitation, soit dans le champ d'application des lois. De la récente expérience de l'économie de guerre et de l'évolution des idées au cours de cette période se dégagent maintenant des tendances significatives au sujet des relations industrielles. Bien que certaines de ces tendances ne soient pas encore précises, elles révèlent cependant que des problèmes sont posés et qu'il importe de les étudier pour les résoudre dans le sens de l'intérêt général. Parmi ces problèmes, il en est un qui ressort nettement de l'ensemble des revendications ouvrières d'après-guerre, aussi bien en Amérique qu'en Europe: c'est celui de la participation ouvrière à la gestion des entreprises. Je n'exposerai ici que les grandes lignes de cette question, sans porter de jugement pratique sur les difficultés que comporte l'application du principe de la participation ouvrière à la gestion.

Tel qu'entendu ici, la participation à la gestion de l'entreprise, c'est la participation non seulement à l'oeuvre de production, mais aussi à l'administration de l'entreprise. Elle implique donc des aspects techniques et économiques qui exigent dans les rangs des syndicats la présence de travailleurs doués de connaissances administratives relativement étendues. Il $\mathrm{y}$ a lieu de distinguer, ainsi que je l'ại déjà fait (voir Bulletin no 3 , premièremière série: les Comités d'entreprises en France), la participation sous forme de conseil. la participation sous forme de contrôle et la participation sous forme de cogestion.

C'est cette dernière qui constitue une innovation, car elle permet aux travailleurs d'une entreprise d'influencer le développement de celle-ci au même titre que les représentants des actionnaires. Le bureau de direction comprend alors deux catégories de directions: lcs uns représentent les intérêts du canital et les seconds les droits des travailleurs. La particination sous forme de conseil est déià en pratique au Canàda nar les comités mixtes à la production. Les comités d'entreprises en France et dans quelques autres pavs de l'Europe sont une application de la participation sous forme de contrôle. On prévoit que ces comités ne sont qu'une étape vers la véritable congestion. Déià les syndicats francais donnent à leurs militants une formation administrative et commerciale en raison de cette évolution vers la cogestion.

Ce développement de la particioation ouvrière à ia gestion de l'entreprise. quelle que soit sa forme. est un indice aui ne trompe pas. Le travailleur doit être intégré à l'entreprise. mais non par le truchement de vagues comités de coopération qui cachent bien mal le désir de brider l'élan syndicaliste. Je ne discute pas pour le moment le principe de la véritable cogestion. Cette réforme de structure, serait-elle désirable et acceptée par l'ensemble du patronat, 'que la classe ouvrière, pas encore suffisamment préparée à ce rôle; enregistrerait un échec, car elle ne semble pas encore préte, du moins au Canada, à assumer ce rôle. C'est parce que je suis un partisan sincère du syndicalisme et que je crois à la contribution essentielle qu'il apportera éventuellement à la transformation de notre régime économique et social, que je fais cette restriction qui n'a d'ailleurs qu'un caractère transitoire.

Mais si la cogestion n'est peut-être pas réalisable actuellement, il en va autrement des deux premières formes de participation à la gestion. Certaines compagnies américaines, sous l'influence d'Eric Johnson, exprésident de la Chanbre de Commerce des Etats-Unis, ont organisé des « junior boards», composés de représentants des travailleurs, qui assistent les bureaux de direction. Il ne saurait être question d'instituer pareille réforme dans l'idée d'endiguer la vague syndicaliste. Toute réforme de structure devra se faire avec la collaboration des syndicats ouvriers, sinon ce sera la faillite. D'autre part, il n'est pas question non plus de confier des responsabilités mal définies à des personnes qui n'ont pas les capacités requises.

En effet, le principe de la hiérarchie des fonctions ne doit jamais être mis de côté. L'application d'un système quelconque de participation à la gestion, quelle que soit sa forme, implique une hiérarchie, c'est-à-dire un ordre. Je ne vois pas comment des représentants des travailleurs dans un organisme de gestion seraient recrutés en majorité dans le département des manoeuvres. De même, comment concevoir que les représentants désignés par les travailleurs ne soient pas des éléments de première qualité. En d'autres termes, la participation à la gestion exige un aménagement rationnel de la représentation des travailleurs dans les conseils de gestion, problème que les conventions collectives de travail devraient prévoir et résoudre.

Du côté de la classe ouvrière, la participation à la gestion implique une prise de conscience nouvelle, c'està-dire l'acquisition de notions tećhniques et économiques indispensables à quiconque aspire à des responsabilités dans l'administration d'une entreprise. On ne doit pas se préoccuper uniquement de former des chefs syndicaux, mais également de donner une éducation technique et économique à tous les travailleurs qui montrent des dispositions suffisantes: C'est sur le plan de l'industrie dans son ensemble qu'il faut envisager la formation d'éléments ouvriers et syndicaux aptes à la gestion. L'expérience que poursuit depuis deux ans la commission d'apprentissage de l'industrie de la chaussure prouve qu'il est possible d'élever le niveau des connaissances professionnelles des travailleurs.

Je viens simplement d'esquisser quelques-uns de: aspects de la participation ouvrière à la gestion de l'entreprise. Ce schéma n'avait qu'un but: provoquer l'étude d'un problème qui deyra être résolu un jour plus ou moins prochain, à savoir l'intégration du travailleur dans la structure économique. De même que pour la liberté svindicale, les eniployeurs qui seront les premiers à aborder cette question sans l'escamoter seront en mesure de s'adapter rapidement aux exigences du progrès social. 